\title{
Prevalence and Factors Associated with Postpartum Depression during the COVID-19 Pandemic among Women in Jeddah, Saudi Arabia: A Cross-Sectional Study
}

\author{
Aisha Ibrahim Tarabay1, Dalal Boogis ${ }^{1}$, Aysha Tariq Tabbakh2*, Raghad Akram Kemawi², \\ Layan Abduljalil Boogis ${ }^{3}$, Abdulrahman Tariq Tabbakh², Maha Mohsen Al-Hadrami2, \\ Manal Mohsen Al-Hadrami ${ }^{4}$
}

\author{
${ }^{1}$ Obstetrics and Gynecology Consultant, King Abdulaziz Hospital, Jeddah, KSA \\ ${ }^{2}$ Medical Intern, IbnSina College, Jeddah, KSA \\ ${ }^{3}$ Medical Student, Battarje Medical College, Jeddah, KSA \\ ${ }^{4}$ Medical Student, IbnSina National College, Jeddah, KSA \\ Email: ^ayotab@gmail.com
}

How to cite this paper: Tarabay, A.I., Boogis, D., Tabbakh, A.T., Kemawi, R.A., Boogis, L.A., Tabbakh, A.T., Al-Hadrami, M.M. and Al-Hadrami, M.M. (2020) Prevalence and Factors Associated with Postpartum Depression during the COVID-19 Pandemic among Women in Jeddah, Saudi Arabia: A Cross-Sectional Study. Open Journal of Obstetrics and Gynecology, 10, 1644-1657.

https://doi.org/10.4236/ojog.2020.10110148

Received: October 28, 2020

Accepted: November 27, 2020

Published: November 30, 2020

Copyright $\odot 2020$ by author(s) and Scientific Research Publishing Inc. This work is licensed under the Creative Commons Attribution International License (CC BY 4.0).

http://creativecommons.org/licenses/by/4.0/ (c) (i) Open Access

\begin{abstract}
Background: Postpartum depression is the most common psychological health problem among females; it begins after the birth of the child and can occur at any time during the first year of delivery. The COVID-19 pandemic is a novel virus that is highly infectious and has several negative psychological impacts on individuals globally. Aim: Coronavirus disease 2019 (COVID-19) has been reported to increase the incidence rate of depression. We investigated the prevalence rate and associated factors of postpartum depression (PPD) among women in Jeddah, Saudi Arabia, during the COVID-19 period, thereby attempting to determine whether and how COVID-19 affected PPD. Methods: This is a cross-sectional study that was conducted on women at one week to six months postpartum using an online questionnaire. SPSS program was used for analyzing data. Results: This study included 150 participated women; $49.3 \%$ were in the age range of 25 - 34 years old. There were $30.7 \%$ reported being primigravida. Regarding the level of depression, there were $60.7 \%$ reported the presence of depression; the depression was affected by some demographics of females such as the education level $(\mathrm{P}=0.021)$ and other factors related to the COVID-19 pandemic such as visiting the doctor during quarantine $(\mathrm{P}=0.049)$, diagnosis with depression by the doctor $(\mathrm{P}=$ 0.006), the impact of the pandemic on depression $(P=0.035)$, experiencing symptoms of depression during pregnancy $(\mathrm{P}=0.005)$, family history $(\mathrm{P}=$ $0.043)$, and difficulties during childbirth during the pandemic period $(\mathrm{P}=$
\end{abstract}


0.03). Conclusion: There was a high prevalence of PPD among women during the COVID-19 period, and it was higher than the prevalence of PPD before the COVID-19 period.

\section{Keywords}

PPD, COVID-19, Prevalence, Associated Factors

\section{Introduction}

Postpartum depression (PPD) is a non-cyclic depression that begins after childbirth in the postpartum period, and it can occur at any time during the first year after delivery [1]. PPD is the most common psychological health issue among females, affecting $10 \%-15 \%$ of females globally [2]. The main characteristics of PPD including emotional stress, anxiety, loss of appetite, tearfulness, guilt feelings, sleep disorders, suicidal thoughts, memory problems, concentration problems, irritability, feeling of weakness, and exhaustion [3] [4] [5].

There are several risk factors associated with PPD, such as life stress, labor pain, family history, socio-economic status, inadequate antenatal care, and nutritional deficiency [3] [4] [5] [6].

The international prevalence of PPD was reported to be $13 \%$; however, the prevalence rates are based on the screening period, the country of the study and the screening method and tool used [3].

A study investigated the prevalence of PPD in Saudi Arabia reported that there was $33.2 \%$ of participants showed PPD symptom risk, with anemia and low hemoglobin being the risk factors for PPD [7]. A study from Riyadh reported that the prevalence of PPD among 174 females was 38.5\%, and there were significant associations between PPD and each of the unsupportive husband and recent stressful events [8]. The prevalence of PPD among postpartum mothers in Jeddah was reported according to the EPDS score, and it was 12.7 with a range of zero to 30. The prevalence of PPD was associated with maternal age, education, occupation, medical problems, monthly income, previous psychological problems, and planning pregnancy [9].

On January $30^{\text {th }}$, the world health organization (WHO) announced the outbreak of the novel coronavirus (COVID-19) as a public health emergency of international concern [10]. COVID-19 is a highly infectious disease that has posed a global health threat [11]. The authorities in Saudi Arabia were monitoring the COVID-19 situation from the time it was first detected, and plans were established to prepare for the potential spread of the disease in the kingdom [12]. However, on March $2^{\text {nd }}$, the first COVID-19 case in Saudi Arabia was confirmed in a traveler returning from Iran through Bahrain with no declaration of his traveling history to Iran [13]. Umrah was completely pended, the two holy mosques in Makkah and Madinah were put for daily closure for cleaning and disinfection, and the schools and universities were depending on remote learning [13]. 
The COVID-19 resulted in significant negative psychological impacts on individuals globally. These impacts include stress, fair, pandemic, anxiety, depression, sleep disorders, insomnia, panic, and impaired quality of life [14]. These effects are close to the effects caused by PPD, so the presence of COVID-19 may enhance the occurrence of PPD. Although there were studies reported on the prevalence of PPD in Saudi Arabia, there was no study that investigated its prevalence during the COVID-19 period, so this study was conducted to assess the prevalence of PPD during the COVID-19 period.

\section{Subjects and Methods}

\subsection{Subjects and Study Design}

This is a cross-sectional study; it was performed during the period from March 2020 to August 2020 using an anonymous online questionnaire. The study included women from one week to 6 months postpartum. The Arabic version of the Edinburgh Postnatal Depression Scale and a questionnaire regarding associated factors were administered to all participants. Approval for the study was obtained before the beginning of the study with an IRB registration number with KACST, KSA: H-02-J-002.

\subsection{Statistical Analysis}

SPSS program version 22 was used to analyze the data; numbers and percents were used to represented qualitative variables. Multivariate logistic regression was used to determine factors that were significantly associated with PPD. $\mathrm{P}$-value at $\leq 0.05$ was considered significant.

\section{Results}

The present study included 150 women. The dominant age of participants was 25 - 34 years old 74 (49.3\%). The large majority were Saudi females 135 (90\%), only 15 (10\%) were non-Saudi. Also, the large majority were married 143 (95.3\%). There were 124 (82.7\%) reported university education, whereas $26(17.3 \%)$ had less than university education. Regarding the job, there 71 (47.3\%) housewives, 63 (42\%) employees, and $16(10.7 \%)$ students. The highest monthly income of more than ten thousand was reported by 43 (28.7\%) of participants. More than half of women, 77 (51.3\%), reported two to four times of pregnancy, whereas 46 (30.7\%) reported being primigravida, and 27 (18\%) reported more than four times of pregnancy. Table 1 shows the demographics and characteristics of the participated women.

We used the Arabic version of the Edinburgh Postnatal Depression Scale, so the depression score was calculated according to that scale. The maximum score of the scale is 30 , the depression is predicted at ten scores and more. There were $91(60.7 \%)$ of participants scored $\geq$ ten scores, whereas 59 (39.3\%) scored less than ten scores, Figure 1.

Investigation of the factors and depression characteristics during the COVID-19 of females was done through 25 questions; the questions and the 


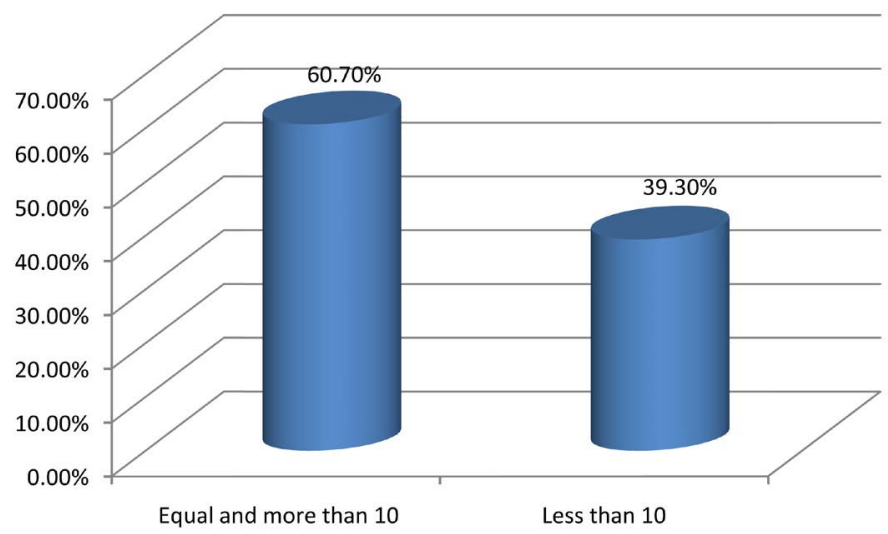

Figure 1. The scores of depression among the participated women.

Table 1. Demographics and characteristics of the participants.

\begin{tabular}{|c|c|}
\hline Demographics & $\begin{array}{c}\text { Description } \\
(\mathrm{n}=150)\end{array}$ \\
\hline \multicolumn{2}{|l|}{ Age } \\
\hline$<25$ & $23(15.3)$ \\
\hline $25-34$ & $74(49.3)$ \\
\hline 35 or more & $53(35.3)$ \\
\hline \multicolumn{2}{|l|}{ Nationality } \\
\hline Saudi & $135(90)$ \\
\hline Non-Saudi & $15(10)$ \\
\hline \multicolumn{2}{|l|}{ Marital status } \\
\hline Married & $143(95.3)$ \\
\hline Divorced/widow & $7(4.7)$ \\
\hline \multicolumn{2}{|l|}{ Scientific level } \\
\hline Less than university & $26(17.3)$ \\
\hline University & $124(82.7)$ \\
\hline \multicolumn{2}{|l|}{ Job } \\
\hline Student & $16(10.7)$ \\
\hline Employee & $63(42)$ \\
\hline Housewife & $71(47.3)$ \\
\hline \multicolumn{2}{|l|}{ Monthly income } \\
\hline$<5 \mathrm{~K}$ & $66(44)$ \\
\hline $5-10 \mathrm{~K}$ & $41(27.3)$ \\
\hline$>10 \mathrm{~K}$ & $43(28.7)$ \\
\hline \multicolumn{2}{|c|}{ The number of pregnancies } \\
\hline Primigravida & $46(30.7)$ \\
\hline $2-4$ times & $77(51.3)$ \\
\hline$>4$ times & $27(18)$ \\
\hline
\end{tabular}


Table 2. The questions related to the COVID-19 period and the depression of females.

\begin{tabular}{|c|c|}
\hline Questions and answers & $\begin{array}{c}\text { Description } \\
(\mathrm{n}=150)\end{array}$ \\
\hline \multicolumn{2}{|c|}{$\begin{array}{l}\text { 1-Did you visit your doctor to monitor your pregnancy during the quarantine } \\
\text { period? }\end{array}$} \\
\hline Yes & $113(75.3)$ \\
\hline No & $37(24.7)$ \\
\hline \multicolumn{2}{|c|}{ 2-Did you find it difficult to visit your doctor during the quarantine period? } \\
\hline Yes & $81(54)$ \\
\hline No & $69(46)$ \\
\hline \multicolumn{2}{|l|}{ 3-Do you suffer from the following chronic diseases? } \\
\hline Yes & $55(36.7)$ \\
\hline No & $95(63.3)$ \\
\hline \multicolumn{2}{|l|}{ 3-Do you suffer from the following chronic diseases? } \\
\hline Anemia & $18(12)$ \\
\hline $\mathrm{DM}$ & $4(2.7)$ \\
\hline $\mathrm{DM}$ & $5(3.3)$ \\
\hline Irritable colon & $15(10)$ \\
\hline Respiratory & $2(1.3)$ \\
\hline Psycho & $3(2)$ \\
\hline Renal & $1(0.7)$ \\
\hline Tumor & $1(0.7)$ \\
\hline Others & $6(4)$ \\
\hline No & $95(63.3)$ \\
\hline \multicolumn{2}{|l|}{ 4-Have you been diagnosed with depression by a doctor? } \\
\hline Yes & $19(12.7)$ \\
\hline No & $131(87.3)$ \\
\hline \multicolumn{2}{|l|}{ 5-How was the state of depression overcome? } \\
\hline Anti-depression TTT & $5(26.3)$ \\
\hline Consult psychiatric & $9(47.4)$ \\
\hline Herbal medicine & $5(26.3)$ \\
\hline \multicolumn{2}{|l|}{ 6-How does the pandemic affect depression? } \\
\hline Increased & $15(78.9)$ \\
\hline No change & $4(21.1)$ \\
\hline \multicolumn{2}{|c|}{ 7-What are the factors that affected your health the most during the pandemic? } \\
\hline Anxiety from infection & $52(34.7)$ \\
\hline Anxiety about transmitting the infection to the child & $35(23.3)$ \\
\hline Stay home & $30(20)$ \\
\hline Loss of support from family and friends & $20(13.3)$ \\
\hline Anxiety about delays receiving health care crisis & $13(8.7)$ \\
\hline
\end{tabular}




\section{Continued}

8-Did you suffer from health problems during pregnancy?

Yes

No

$107(71.3)$

9-Did you take medicine regularly during the quarantine period?

Yes

$31(72.1)$

No

$12(27.9)$

10-Is your husband cooperating with the offspring?

Yes

No

11-Are there family problems?

Yes

No

So the answer is yes, its type

Multipleour marriage

Divorce

12-Is there a history of depression before pregnancy?

Yes

No

$131(87.3)$

If yes, did he require treatment?

Yes

$10(52.6)$

No

13-Did, you find symptoms of depression during pregnancy?

Yes

No

$111(74)$

14-Is there a family history of mental illness or depression?

Yes

No

15-The type of the current born

Male

Female

16-The type of the previous born

Male

Female

17-Is your husband satisfied with the current pregnancy?

Yes

$136(90.7)$

No

$14(9.3)$ 


\section{Continued}

18-Did you have a desire for this pregnancy?

19-Were you satisfied with the sex?

No

Don't care

20-How was the birth

21-Did you suffer from difficulties during childbirth?

22-Did you find it difficult to reach the hospital during childbirth during the quarantine period?

Yes

No

23-Has breastfeeding started?

Yes

24-Have you been diagnosed with Corona disease?

$$
\text { Yes }
$$

25-Compared to before the pandemic, how do you evaluate health care?

Better

answers of females are shown in Table 2. 113 (75.3\%) reported visiting the doctor to monitor their pregnancy during the quarantine period. More than half of participants, 81 (54\%), reported finding difficulties in visiting the doctor during the quarantine period. There were 55 (36.7\%) reported suffering from chronic diseases, and the most reported chronic diseases included; anemia 18 (12\%), and irritable colon syndrome 15 (10\%). There were 19 (12.7\%) reported being diagnosed with depression; the most common action to overcome the depression was consulting psychiatric 9 (47.4\%). Most of the females reported that the COVID-19 pandemic increased their depression 15 (78.9\%). The most-reported factors affected their health during the pandemic included; anxiety from the infection 52 (34.7\%), anxiety about the transmission of the infection to the child 35 
(23.3\%), staying at home $30(20 \%)$, and anxiety about delays receiving health care crisis $13(8.7 \%)$. Only $43(28.7 \%)$ reported suffering health problems during pregnancy. There were $31(72.1 \%)$ reported administrating the medicine regularly during the quarantine period. The large majority reported husband cooperation $122(81.3 \%)$; there was $13(8.7 \%)$ reported the presence of family problems, and the most reported problem was multiple marriages 7 (53.8\%). The majority of females reported no history of depression before pregnancy 131 $(87.3 \%)$, whereas $19(12.7 \%)$ reported the presence of such history, and 10 (52.6\%) reported that this previous depression required treatment. Only 39 (26\%) of females reported having symptoms of depression during pregnancy; there was $69(46 \%)$ reported that the gender of the current born was male, whereas 81 (54\%) reported the gender was female. There were $70(67.3 \%)$ reported the gender of the previous born was male, and 34 (32.7\%) reported females. A few numbers of participated females 24 (16\%) reported having a family history of mental illness and depression. The large majority of our participants reported that their husbands are satisfied with their current pregnancy 136 (90.7\%), 118 (78.7\%) of women reported that they have a desire for this pregnancy, and 128 $(85.3 \%)$ were satisfied with the gender of the baby. More than half of females delivered via vaginal route $94(62.7 \%)$, and there was $62(41.3 \%)$ reported suffering from difficulties during childbirth. There was only 15 (10\%) reported having difficulties reaching the hospital during childbirth during the quarantine period. More than half of women reported starting breastfeeding 98 (65.3\%). There was only $14(9.3 \%)$ reported that they were diagnosed with the coronavirus. By comparing the healthcare before the pandemic, there were $43(28.7 \%)$ reported it was better, 89 (59.3\%) reported it is the same, and 18 (12\%) was worse.

The factors associated with depression during the COVID-19 period were investigated, and they are shown in Table 3. The level of depression was significantly affected by the education level $(\mathrm{P}=0.021)$, difficulties during quarantine to visit the doctor $(\mathrm{P}=0.049)$, the diagnosis with depression by a doctor $(\mathrm{P}=$ 0.006), the impact of the pandemic on the depression $(P=0.035)$, the experience of symptoms of depression during pregnancy $(\mathrm{P}=0.005)$, the family history of mental illness or depression $(\mathrm{P}=0.043)$, and suffering from difficulties during childbirth during the quarantine period $(\mathrm{P}=0.03)$.

\section{Discussion}

This is the first Saudi study to investigate the postpartum depression during the COVID-19 pandemic period. We found that $60.7 \%$ of 150 females experienced PPD during the COVID-19 period. A study from China reported the prevalence of PPD during the COVID-19 period as 30\% [11], which was much lower than our findings, although we used the same scale used to ass the PPD as the Chinese study used. These variations may return to other factors related to the demographics of participants, factors related to the application of quarantine, or the availability of providing health care. A study from Turkey showed that among 
Table 3. Comparison of all factors regarding depression total score.

\begin{tabular}{|c|c|c|c|}
\hline & \multicolumn{2}{|c|}{ Total Score } & \multirow[b]{2}{*}{ P value } \\
\hline & $\begin{array}{c}\geq 10 \\
(n=91)\end{array}$ & $\begin{array}{c}<10 \\
(n=59)\end{array}$ & \\
\hline \multicolumn{4}{|l|}{ age } \\
\hline$<25$ & $15(16.5)$ & $8(13.6)$ & 0.539 \\
\hline $25-34$ & $47(51.6)$ & $27(45.8)$ & \\
\hline 35 or more & $29(31.9)$ & $24(40.7)$ & \\
\hline \multicolumn{4}{|l|}{ Nationality } \\
\hline Saudi & $81(89)$ & $54(91.5)$ & 0.616 \\
\hline Non-Saudi & $10(11)$ & $5(8.5)$ & \\
\hline \multicolumn{4}{|l|}{ Marital status } \\
\hline Married & $87(95.6)$ & $56(94.9)$ & 1.000 \\
\hline Divorced/widow & $4(4.4)$ & $3(5.1)$ & \\
\hline \multicolumn{4}{|l|}{ Scientific level } \\
\hline Less than university & $21(23.1)$ & $5(8.5)$ & 0.021 \\
\hline University & $70(76.9)$ & $54(91.5)$ & \\
\hline \multicolumn{4}{|l|}{ Job } \\
\hline Student & $11(12.1)$ & $5(8.5)$ & 0.234 \\
\hline Employee & $42(46.2)$ & $21(35.6)$ & \\
\hline Housewife & $38(41.8)$ & $33(55.9)$ & \\
\hline \multicolumn{4}{|l|}{ Monthly income } \\
\hline$<5 \mathrm{~K}$ & $39(42.9)$ & $27(45.8)$ & 0.300 \\
\hline $5-10 \mathrm{~K}$ & $22(24.2)$ & $19(32.2)$ & \\
\hline$>10 \mathrm{~K}$ & $30(33)$ & $13(22)$ & \\
\hline \multicolumn{4}{|c|}{ The number of pregnancies } \\
\hline Primigravida & $32(35.2)$ & $14(23.7)$ & 0.156 \\
\hline 2 - 4 times & $41(45.1)$ & $36(61)$ & \\
\hline$>4$ times & $18(19.8)$ & $9(15.3)$ & \\
\hline \multicolumn{4}{|c|}{$\begin{array}{l}\text { Did you visit your doctor to monitor your } \\
\text { pregnancy during the quarantine period? }\end{array}$} \\
\hline Yes & $66(72.5)$ & $47(79.7)$ & 0.322 \\
\hline No & $25(27.5)$ & $12(20.3)$ & \\
\hline \multicolumn{4}{|c|}{$\begin{array}{l}\text { Did you find it difficult to visit your doctor } \\
\text { during the quarantine period? }\end{array}$} \\
\hline Yes & $55(60.4)$ & $26(44.1)$ & 0.049 \\
\hline No & $36(39.6)$ & $33(55.9)$ & \\
\hline \multicolumn{4}{|c|}{ Do you suffer from the following chronic diseases? } \\
\hline Yes & $37(40.7)$ & $18(30.5)$ & 0.208 \\
\hline No & $54(59.3)$ & $41(69.5)$ & \\
\hline
\end{tabular}




\section{Continued}

Have you been diagnosed with depression by a doctor?

Yes

No

How was the state of depression overcome?

Anti-depression TTT

Consult psychiatric

Herbal medicine

How does pandemic affect depression?

$$
\begin{aligned}
& \text { Increased } \\
& \text { No change }
\end{aligned}
$$

What are the factors that affected your health the most during the pandemic?

$$
\text { Anxiety from infection }
$$

Anxiety about transmitting the infection to the child

Stay home

Loss of support from family and friends

Anxiety about delays receiving health care crisis

Did you suffer from health problems during pregnancy?

$$
\text { Yes }
$$$$
\text { No }
$$

Did you take medicine regularly during the quarantine period?

$$
\text { Yes }
$$$$
\text { No }
$$

Is the husband cooperating with the offspring?

$$
\text { Yes }
$$$$
\text { No }
$$

Are there family problems

$$
\text { Yes }
$$$$
\text { No }
$$

The answer is yes, its type.

Multiple marriages

Divorce

Is there a history of depression before pregnancy?

$$
\text { Yes }
$$$$
\text { No }
$$

If yes, did he require treatment?

$$
\text { Yes }
$$

No

$$
\begin{array}{cc}
17(18.7) & 2(3.4) \\
74(81.3) & 57(96.6)
\end{array}
$$

$\begin{array}{cc}26(28.6) & 26(44.1) \\ 23(25.3) & 12(20.3) \\ 20(22) & 10(16.9) \\ 13(14.3) & 7(11.9) \\ 9(9.9) & 4(6.8)\end{array}$

$7(70) \quad 0(0)$




\section{Continued}

\begin{tabular}{|c|c|c|c|}
\hline \multicolumn{4}{|c|}{ Did you find symptoms of depression during pregnancy? } \\
\hline Yes & $31(34.1)$ & $8(13.6)$ & 0.005 \\
\hline No & $60(65.9)$ & $51(86.4)$ & \\
\hline \multicolumn{4}{|c|}{ Is there a family history of mental illness or depression? } \\
\hline Yes & $19(20.9)$ & $5(8.5)$ & 0.043 \\
\hline No & $72(79.1)$ & $54(91.5)$ & \\
\hline \multicolumn{4}{|c|}{ How was the birth } \\
\hline Vaginal & $53(58.2)$ & $41(69.5)$ & 0.164 \\
\hline CS & $38(41.8)$ & $18(30.5)$ & \\
\hline \multicolumn{4}{|c|}{ Did you suffer from difficulties during childbirth? } \\
\hline Yes & $44(48.4)$ & $18(30.5)$ & 0.030 \\
\hline No & $47(51.6)$ & $41(69.5)$ & \\
\hline \multicolumn{4}{|c|}{$\begin{array}{l}\text { Did you find it difficult to reach the hospital during } \\
\text { childbirth during the quarantine period? }\end{array}$} \\
\hline Yes & $11(12.1)$ & $4(6.8)$ & 0.290 \\
\hline No & $80(87.9)$ & $55(93.2)$ & \\
\hline \multicolumn{4}{|c|}{ Have you been diagnosed with Corona disease? } \\
\hline Yes & $6(6.6)$ & $8(13.6)$ & 0.152 \\
\hline No & $85(93.4)$ & $51(86.4)$ & \\
\hline \multicolumn{4}{|c|}{$\begin{array}{l}\text { Compared to before the pandemic, } \\
\text { how do you evaluate health care? }\end{array}$} \\
\hline Better & $27(29.7)$ & $16(27.1)$ & 0.077 \\
\hline Same & $49(53.8)$ & $40(67.8)$ & \\
\hline Worse & $15(16.5)$ & $3(5.1)$ & \\
\hline
\end{tabular}

${ }^{\star}$ Chi-square test.

126 females, there was $12 \%$ only having the risk for PPD [14]. The Turkish study also used the EDP scale as we used; however, the prevalence rate in our study still higher among the studies conducted in other countries.

The prevalence of PPD in Saudi Arabia, as reported in several studies before the pandemic, ranged from $17.8 \%$ to $38.5 \%$ [9] [15]. Our findings showed a high elevation in the prevalence rate of PPD in Saudi Arabia. These findings were in agreement with the Canadian study that reported that there was a significant elevation in depression and anxiety symptoms compared to similar pre-pandemic among pregnant women, with $37 \%$ showed depression symptoms, and $57 \%$ showed anxiety symptoms [16].

This study did not examine the prevalence rate of PPD before COVID-19 pandemic and thus we cannot conclude that COVID-19 actually increased the incidence of PPD. However, previous data on the incidence of PPD in Saudi Arabia was much lower than that obtained here. Thus, we believe that the 
present prevalence rate of PPD was much higher than that of before-COVID-19".

The current study investigated the impact of the COVID-19 pandemic on the women and the depression they suffered. The quarantine was obligated during the COVID-19 period to reduce the transmission of the virus. Varied percents of our participants reported that they didn't visit the doctor during the quarantine, there were difficulties in visiting the doctor during the quarantine period, the COVID-19 pandemic increased the depression of participants, anxiety affected the health of participants during the pandemic, and the presence of difficulties to reach the hospital during childbirth during the quarantine. These findings indicated the negative impact of the COVID-19 pandemic period and quarantine on the women.

It was reported that the difficulty in accessing professional medical care might be a source of anxiety for pregnant women [17].

By investigating the factors associated with PPD during the COVID-19 pandemic period, this study showed that university education was associated with experiencing PPD. Another factor was that the doctor didn't diagnose depression, no experience of depression symptoms during pregnancy, no family history of depression or mental illness; these factors related to the demographic and characteristics of participants. Other factors associated with PPD and related to the COVID-19 period, including; finding difficulties in visiting the doctor during the quarantine period, increases of the depression during the pandemic, and suffering difficulties during childbirth.

Other factors associated with PPD during the pandemic period were reported from a study from China, and they included immigrant women, persistent fever, poor social support, concerns about contracting COVID-19, and certain precautionary measures [11]. A study from Turkey reported low income, higher education levels, previous psychiatric illness, and having newborn needs NICUS were associated significantly with PPD [14]. In agreement with our study, the high level of education was associated with PPD.

Demographic factors associated with PPD didn't change before and after the pandemic and seemed to have the same impact enhancing the occurrence of PPD, where it was reported to form a study from Central Nepal that the education level was associated with the prevalence of PPD. This study from Central Nepal was conducted from 2017 to 2018 and published in 2019 before the pandemic [18].

\section{Conclusion}

There was a high prevalence of PPD among women during the COVID-19 period. Compared with the period before the COVID-19 pandemic, the prevalence during the COVID-19 was higher than before the pandemic. The factors associated with the prevalence of PPD included demographic factors such as education, family history. However, the pandemic COVID-19 increased the prevalence of PPD by some factors, including the quarantine due to the pandemic and 
increased depression resulting in the pandemic as reported by the participants. Additionally, strategies have to be developed by health care authorities to design recommendations and actions to prevent occurrence of post-partum depression during the pandemic.

\section{Conflicts of Interest}

The authors declare no conflicts of interest regarding the publication of this paper.

\section{References}

[1] Giri, R.K., Khatri, R.B., Mishra, S.R., Khanal, V., Sharma, V.D. and Gartoula, R.P. (2015) Prevalence and Factors Associated with Depressive Symptoms among Post-Partum Mothers in Nepal. BMC Research Notes, 8, Article No. 111. https://doi.org/10.1186/s13104-015-1074-3

[2] Vigod, S.N., Villegas, L., Dennis, C.L. and Ross, L.E. (2010) Prevalence and Risk Factors for Postpartum Depression among Women with Preterm and Low-BirthWeight Infants: A Systematic Review. BJOG, 117, 540-550. https://doi.org/10.1111/j.1471-0528.2009.02493.x

[3] Alharbi, A. and Abdulghani, H.M. (2014) Risk Factors Associated with Postpartum Depression in the Saudi Population. Neuropsychiatric Disease and Treatment, 10, 311-316. https://doi.org/10.2147/NDT.S57556

[4] Villegas, L., McKay, K., Dennis, C.L. and Ross, L.E. (2011) Postpartum Depression among Rural Women from Developed and Developing Countries: A Systematic Review. The Journal of Rural Health, 27, 278-288. https://doi.org/10.1111/j.1748-0361.2010.00339.x

[5] Turkcapar, A.F., Kadığlu, N., Aslan, E., Tunc, S., Zayıfoğlu, M. and Mollamahmutoğlu, L. (2015) Sociodemographic and Clinical Features of Postpartum Depression among Turkish Women: A Prospective Study. BMC Pregnancy Childbirth, 15, 108. https://doi.org/10.1186/s12884-015-0532-1

[6] Gavin, N.I., Gaynes, B.N., Lohr, K.N., Meltzer-Brody, S., Gartlehner, G. and Swinson, T. (2005) Perinatal Depression: A Systematic Review of Prevalence and Incidence. Obstetrics \& Gynecology, 106, 1071-1083. https://doi.org/10.1097/01.AOG.0000183597.31630.db

[7] Al Nasr, R.S., Altharwi, K., Derbah, M.S., Gharibo, S.O., Fallatah, S.A., Alotaibi, S.G., Almutairi, K.A. and Asdaq, S.M. (2020) Prevalence and Predictors of Postpartum Depression in Riyadh, Saudi Arabia: A Cross Sectional Study. PLoS ONE, 15, e0228666. https://doi.org/10.1371/journal.pone.0228666

[8] Alamoudi, D.H., Almrstani, A.M.S., Bukhari, A., Alamoudi, L.H., Alsubaie, A.M., Alrasheed, R.K., et al. (2017) Prevalence and Factors Associated with Depressive Symptoms among Post-Partum Mothers in Jeddah. International Journal of Advanced Research, 5, 1542-1550. https://doi.org/10.21474/IJAR01/3314

[9] Suhitharan, T., Pham, T.P., Chen, H., Assam, P.N., Sultana, R., Han, N.L., Tan, E.C. and Sng, B.L. (2016) Investigating Analgesic and Psychological Factors Associated with Risk of Postpartum Depression Development: A Case-Control Study. Neuropsychiatric Disease and Treatment, 12, 1333-1339. https://doi.org/10.2147/NDT.S105918

[10] Mahase, E. (2020) China Coronavirus: WHO Declares International Emergency as Death Toll Exceeds 200. BMJ, 368, m408. https://doi.org/10.1136/bmj.m408 
[11] Xiong, R., Liu, Y., Liang, P., Wang, Y. and Shi, S. (2020) Prevalence and Factors Associated with Postpartum Depression during the Covid-19 Pandemic among Women in Guangzhou, China: A Cross-Sectional Study.

[12] Yezli, S. and Khan, A. (2020) COVID-19 Social Distancing in the Kingdom of Saudi Arabia: Bold Measures in the Face of Political, Economic, Social and Religious Challenges. Travel Medicine and Infectious Disease, 37, Article ID: 101692. https://doi.org/10.1016/j.tmaid.2020.101692

[13] Algaissi, A.A., Alharbi, N.K., Hassanain, M. and Hashem, A.M. (2020) Preparedness and Response to COVID-19 in Saudi Arabia: Building on MERS Experience. Journal of Infection and Public Health, 13, 834-838. https://doi.org/10.20944/preprints202004.0018.v1

[14] Koyuncu, K., Alan, Y., Sakin, Ö., Aktaş, H.A. and Angın, A.D. (2020) Conditions Affecting Postpartum Depression in the Covid-19 Pandemic. Medical Science and Discovery, 7, 611-616. https://doi.org/10.36472/msd.v7i8.413

[15] Alasoom, L.I. and Koura, M.R. (2014) Predictors of Postpartum Depression in the Eastern Province Capital of Saudi Arabia. Journal of Family Medicine and Primary Care, 3, 146. https://doi.org/10.4103/2249-4863.137654

[16] Lebel, C., MacKinnon, A., Bagshawe, M., Tomfohr-Madsen, L. and Giesbrecht, G. (2020) Elevated Depression and Anxiety among Pregnant Individuals during the COVID-19 Pandemic. Journal of Affective Disorders, 277, 5-13. https://doi.org/10.1016/j.jad.2020.07.126

[17] Simó, S., Z_uñiga, L., Izquierdo, M.T., et al. (2019) Effects of Ultrasound on Anxiety and Psychosocial Adaptation to Pregnancy. Archives of Women's Mental Health, 22, 511-518. https://doi.org/10.1007/s00737-018-0918-y

[18] Dawadi, P., Bhatta, A.S. and Shakya, J. (2020) Factors Associated with Postpartum Depressive Symptoms in Community of Central Nepal. Psychiatry Journal, 2020, Article ID: 8305304. https://doi.org/10.1155/2020/8305304 